\title{
The Effects of Adding Inert Material and Electrode Powder in a Coal
}

\author{
Lakshya Dev \\ BIT, Mesra
}

\begin{abstract}
The research done in this project is concerning improving the quality of coal which is used for coal manufacture.Two processes have been dealt in detail in this research which depict on how the quality of coal is effected by adding certain foreign elements in its composition that either degrades or improves its characteristics. The two processes are namely CSN( crucible swelling number test) and LTGK(Low temperature grey-king test).These tests and their significances have been dealt and the various coals used for testing have been specified.
\end{abstract}

Keywords - Coking Coal,CSN,Electrode powder,inert material,LTGK

\section{INTRODUCTION}

Aim of this project is to find the effects of adding coke and graphite in a coal sample and observe the changes in its coke forming capacity based on the CSN(Crucible Swelling Number) and LTGK(Low Temperature Grey King Test) values.

Theoretically, the coking properties of coal should decrease as the addition of inert material which does not have any coking property would decrease the net coke forming ability of the mixture. We do the experiment in different concentrations of coal and graphite and coke in the mixture in order to find out the optimum amount of inert material required in the mixture that would first affect the CSN and LTGK values.

\section{IMPORTANCE OF THE RESEARCH:}

It is necessary to compare the different CSN and LTGK values of different coke forming coal and to find out the reasons behind the decrease in coking properties of the coal mixture. The coal with lower CSN values will naturally have higher content of inert material and thus in coke forming they would produce poor quality of coke which would result in poor efficiency of coke oven battery. This study is important in increasing the efficiency of coking methods and thus paves way for increase in income through the use of good quality coal and thus improving returns for the industry which eventually is the main aim.

\section{RESEARCH ANALYSIS}

Size analysis: For size analysis we took a small amount of sample and tried to pass it through the 72 mesh. The passed amount of the sample was collected in the collector fitted below the mesh. The sample was grinded by hand until entire sample passed through the 72 mesh. Next the sample was passed through the 100 mesh and the amount of sample collected on and under the mesh was collected and weighed. The same step was repeated for the 150 mesh. The following size analysis was made.

Coke Powder Size Analysis 


\begin{tabular}{|c|c|c|}
\hline 150 MESH & 46.39gm & $49.4821 \%$ \\
\hline 200 MESH & $17.67 \mathrm{gm}$ & $18.8681 \%$ \\
\hline $350 \mathrm{MESH}$ & $28.42 \mathrm{gm}$ & $30.3470 \%$ \\
\hline & & \\
\hline & & \\
\hline
\end{tabular}

Electrode Powder Size Analysis

\begin{tabular}{|l|l|l|}
\hline $150 \mathrm{MESH}$ & $33.61 \mathrm{gm}$ & $56.24 \%$ \\
\hline $200 \mathrm{MESH}$ & $16.84 \mathrm{gm}$ & $28.1799 \%$ \\
\hline $350 \mathrm{MESH}$ & $8.82 \mathrm{gm}$ & $14.759 \%$ \\
\hline$-350 \mathrm{MESH}$ & $0.49 \mathrm{gm}$ & $0.82 \%$ \\
\hline
\end{tabular}

\section{CSN(CRUCIBLE SWELling NumBER):}

The sample was taken and measured in a crucible until it reached 1 gram. Different blend of the sample was made with coke and graphite powder and the mixture was mixed thoroughly, it was then settled and the surface made smith by tapping it approximately 12 times. The sample was then heated in a CSN furnace for 2.5 minutes until the volatile matter escaped at 820 degree celsius. The sample was then taken out and then the readings were taken.

. Three to five buttons are made for each sample, and the average of the profile numbers is taken as the freeswelling index. The shape, or profile, of the buttons determines the free-swelling index of the coal. Anthracite does not usually fuse or exhibit a free-swelling index, whereas the free-swelling index of bituminous coal will increase as the rank increases from high-volatile $\mathrm{C}$ bituminous coal to the low-volatile bituminous coal. Some problems associated with the method are the proper heating rate, oxidation or weathering of the coal sample, and an excess of fine coal in the analysis sample.

Sample C-15-035

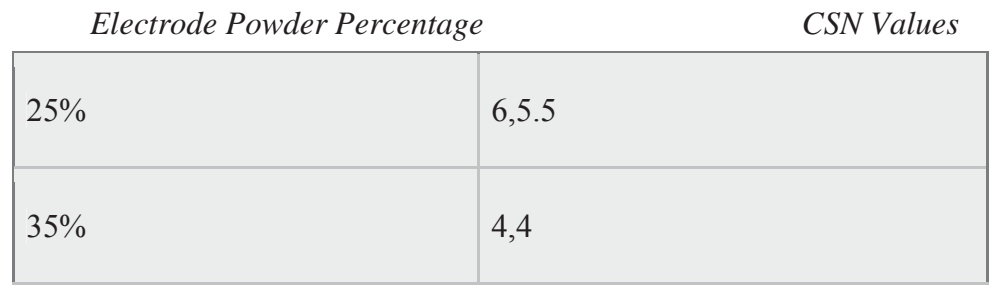




\begin{tabular}{|l|l|}
\hline $45 \%$ & $2.5,2.5$ \\
\hline
\end{tabular}

Sample C-15-035

Coke powder Percentage
\begin{tabular}{|l|l|}
\hline $0 \%$ & $6.5,6.5$ \\
\hline $2.5 \%$ & $7,6.5$ \\
\hline $5 \%$ & $6.5,6.5$ \\
\hline $10 \%$ & $6.5,6.5$ \\
\hline $15 \%$ & $6.5,6.5$ \\
\hline $20 \%$ & $6,6.5$ \\
\hline $25 \%$ & $5.5,5.5$ \\
\hline $30 \%$ & 5,5 \\
\hline $35 \%$ & $4,3.5$ \\
\hline $40 \%$ & $3,2.5$ \\
\hline $50 \%$ & $1.5,1.5$ \\
\hline $60 \%$ & $1.5,1.5$ \\
\hline
\end{tabular}

Sample C-15-035

\begin{tabular}{|l|l|}
\hline Electrode Powder Percentage & \multicolumn{1}{c|}{ CSN Values } \\
\hline $25 \%$ & $6,5.5$ \\
\hline $35 \%$ & 4,4 \\
\hline $45 \%$ & $2.5,2.5$ \\
\hline
\end{tabular}




\section{C-15-036}

Coke powder (\%) CSN Values

\begin{tabular}{|l|l|}
\hline $0 \%$ & $6.5,6.5$ \\
\hline $25 \%$ & $5.5,6$ \\
\hline $35 \%$ & 4,4 \\
\hline $45 \%$ & $3,2.5$ \\
\hline
\end{tabular}

Electrode Powder (\%) CSN Values

\begin{tabular}{|l|l|}
\hline $25 \%$ & 6,6 \\
\hline $35 \%$ & $4.5,4.5$ \\
\hline $45 \%$ & $2.5,2.5$ \\
\hline
\end{tabular}

C-15-039

\begin{tabular}{|c|c|}
\hline Coke powder (\%) & CSN Values \\
\hline $0 \%$ & $7,7.5$ \\
\hline $25 \%$ & $4.5,4$ \\
\hline $30 \%$ & 4,4 \\
\hline $35 \%$ & $2,2.5$ \\
\hline
\end{tabular}




\begin{tabular}{|c|c|}
\hline Elec & CSN Values \\
\hline $25 \%$ & $4.5,4.5$ \\
\hline $30 \%$ & $4,3.5$ \\
\hline $35 \%$ & $2,2.5$ \\
\hline
\end{tabular}

$\begin{aligned} & \text { C-15-040 } \\
& \text { Coke powder (\%) }\end{aligned}$
\begin{tabular}{|l|l|}
\hline $0 \%$ & $7,7.5$ \\
\hline $25 \%$ & $3.5,3.5$ \\
\hline $30 \%$ & $4,3.5$ \\
\hline $35 \%$ & $2.5,2.5$ \\
\hline
\end{tabular}

\begin{tabular}{|l|l|}
\hline Electrode Powder (\%) & \multicolumn{1}{c|}{ CSN Values } \\
\hline $25 \%$ & $5.5,6$ \\
\hline $30 \%$ & $3.5,4$ \\
\hline $35 \%$ & $2.5,3$ \\
\hline
\end{tabular}

\section{RESULT}

A high CSN value denotes a better property of coke for coal making purpose. The best coking values obtained was for C-15-039 and this indicated that it was best suited for manufacturing of coke.

\section{LTGK(LOW TEMPERATURE GREY-KING TEST)}

In this test 20 gram of sample was measured with different concentration and was added carefully to a retort. The sample was then kept in the furnace at about 300 degree Celsius, it was then left in the furnace until it reached a temperature of 600 degrees. The sample was then taken out and allowed to cool, it was then taken out and compared in a pre determined chart and the LTGK values were taken and compared. 
VII. EXPERIMENTAL RESULT

\begin{tabular}{|l|l|l|l|}
\hline COAL & COKE & COAL & LTGK VALUE \\
\hline C-15-114 & $5 \mathrm{gm}$ & $15 \mathrm{gm}$ & G5 \\
\hline C-15-035 & $4 \mathrm{gm}$ & $16 \mathrm{gm}$ & G7 \\
\hline C-15-036 & $4 \mathrm{gm}$ & $16 \mathrm{gm}$ & G7 \\
\hline C-15-035 & $6 \mathrm{gm}$ & $14 \mathrm{gm}$ & G5 \\
\hline C-15-036 & $6 \mathrm{gm}$ & $14 \mathrm{gm}$ & G6 \\
\hline C-15-039 & $5 \mathrm{gm}$ & $15 \mathrm{gm}$ & D(error) \\
\hline C-15-040 & $5 \mathrm{gm}$ & $15 \mathrm{gm}$ & D(error) \\
\hline C-15-035 & $5 \mathrm{gm}$ & $15 \mathrm{gm}$ & F \\
\hline
\end{tabular}

\section{RESULT}

A value of G5 and other higher values in G's indicate a better coking coal.There was a better result for coal samples C-15-114 and C-15-035

\section{REFERENCES}

[1] "Cokemaking: The SunCoke Way"

[2] Dawson, Andrew. "Activated charcoal: a spoonful of sugar". Australian Prescriber.

[3] "charcoal: powdered, compressed, willow and vine". Muse Art and Design. Muse Art and Design.

[4] "Coke Ovens". The Friends of the Cumberland Trail.

[5] "Manufacture of Coke at Salem No. 1 Mine Coke Works". Path of the old miner.

[6] Martin, Scott C. Killing Time: Leisure and Culture in Southwestern Pennsylvania, 1800-1850. Pittsburgh, PA: University of Pittsburgh Press.

[7] Cooper, Eileen Mountjoy. "History of Coke". Special Collections \& Archives: Coal Dust, The Early Mining Industry of Indiana County. Indiana University of Pennsylvania.

[8] Peckham, Stephen (1880). Special Reports on Petroleum, Coke, and Building Stones. United States Census Office. 10th census. p. 53.

[9] Warren, Kenneth (2001). Wealth, Waste, and Alienation: Growth and Decline in the Connellsville Coke Industry. Pittsburgh, PA: University of Pittsburgh.

[10] "charcoal: powdered, compressed, willow and vine". Muse Art and Design. Muse Art and Design. 7 September 2011. Retrieved 27 May 2012. 